Original Research Paper

\title{
Identification of Erosion Hotspot Area using GIS and MCE Technique for Koga Watershed in the Upper Blue Nile Basin, Ethiopia
}

\author{
${ }^{1}$ Tewodros T. Assefa, ${ }^{2}$ Manoj K. Jha, ${ }^{3}$ Seifu A Tilahun, \\ ${ }^{3}$ Ephrem Yetbarek, ${ }^{3}$ Anwar A Adem and ${ }^{4}$ Abeyou Wale \\ ${ }^{I}$ Energy and Environmental System, North Carolina A and T State University, Greensboro, USA \\ ${ }^{2}$ Civil, Architectural and Environmental Engineering, North Carolina A and T State University, USA \\ ${ }^{3}$ School of Civil and Water Resource Engineering, Bahir Dar University, Bahir Dar, Ethiopia \\ ${ }^{4}$ Cornell University, Ithaca, New York, USA
}

\author{
Article history \\ Received: 31-03-2015 \\ Revised: 26-04-2015 \\ Accepted: 22-06-2015 \\ Corresponding Author: \\ Tewodros T. Assefa \\ Energy and Environmental \\ System, North Carolina A and T \\ State University, Greensboro, \\ USA \\ Email: tassefa@aggies.ncat.edu
}

\begin{abstract}
Soil erosion is a serious threat in Ethiopian highlands. Continuous land degradation resulted in loss of fertile top soil leading to low agricultural productivity. In addition, excessive soil erosion from Koga Watershed in upper catchment to an artificial reservoir (Koga Dam reservoir) is substantially reducing its service life. Community participatory based effective watershed management strategies may have tremendous potential to reduce soil erosion. However, it is not practical to implement management interventions in the entire basin. This study aims to identify and map erosion hotspot areas in Koga Watershed to assist local government decision towards implementing watershed management strategies. Multi Criteria Evaluation (MCE) technique was integrated with Geographic Information System (GIS). For these analysis four major factors: Topography, soil, land use and potential location of gullies were considered. Each of these was processed and analyzed for its potential contribution to erosion on a pixel by pixel basis. The factors were weighted using pair-wise comparison matrix and weights were combined using Weighted Overlay Tool of ArcGIS Spatial Analyst Toolbox to obtain the final erosion hotspot map. The results found that $2 \%$ (440 ha) to be highly sensitive, $43 \%(9,460 \mathrm{ha})$ to be moderately sensitive, $16 \%$ $(3,520 \mathrm{ha})$ to be marginally sensitive and $32 \%$ (7,040 ha) currently not sensitive. The remaining $7 \%$ of the watershed area $(22,000 \mathrm{ha})$ was constraint to erosion. The lowland area near the dam was found to be found most sensitive for erosion and sedimentation.
\end{abstract}

Keywords: Erosion Hotspot, Koga Watershed, MCE, GIS, Ethiopia

\section{Introduction}

Excessive soil erosion in the highlands of Ethiopia brought reduced agricultural productivity. Furthermore, natural and artificial reservoirs are suffering from sedimentation and constructed dams are ceased functioning before their service life. Lack of effective watershed management system and poor land use practices played significant role in land degradation in the region (Setegn et al., 2009). According to the Ethiopian highland reclamation study (Yilma and Awulachew, 2009), in the mid 1980's, 27 million hectare or almost $50 \%$ of the high land area was significantly eroded, 14 million hectare seriously eroded and over 2 million hectare were beyond reclamation. Rate of soil erosion is increasing alarmingly necessitating design of proper watershed management strategies. Recently constructed Koga dam reservoir is one of the affected reservoirs in the basin. Its storage volume is substantially reducing because of siltation. The siltation rate is high (100$200 \mathrm{Mt} / \mathrm{ha} / \mathrm{yr}$.) and $50 \%$ is supplied from agricultural lands in the form of sheet and rill erosion (Reynolds, 2012). This adversely results in constrained irrigation 
supply to farmlands. Field visit witnessed inability of Koga dam reservoir to serve some farmlands which are originally included in the design.

Cultivation became infeasible in several parts of Koga Watershed; however and farmers continue to cultivate marginal lands (Mengstie, 2009). Current soil and water conservation practices in Koga Watershed are focused at the highland areas which are highly degraded and have limited production potential. However, this effort could not show significant erosion reduction to date (Mengstie, 2009). Strategic watershed management interventions should focus on erosion sensitive portion of the catchment to prevent further land degradation and siltation to the dam. Lack of finer resolution spatial data and closely installed hydrometeorological data hindered spatial analysis of erosion generation. Setegn et al. (2009) delineated erosion sensitive area for Lake Tana Basin considering steep slope as the main source of erosion (infiltration excess runoff mechanism). However, the saturated area could be the main source of erosion and the dominant runoff mechanism is uncertain for the wider basin.

Understanding the dominant runoff mechanisms (infiltration excess or saturation) is essential to identify watershed management priority areas. Both mechanisms could happen in the same watershed while one dominate the other depending on hydrological properties, moisture content, slope and other factors. In a recent study conducted to nearby experimental watershed, Debremawi (Tilahun et al., 2014) showed that the infiltration capacity were exceeded by rainfall intensity during only 1.5 and $4 \%$ of the time in 2010 and 2011, respectively, indicating the dominance of saturation excess runoff mechanism. These findings indicate that the study area (Koga Watershed) is also dominated by saturation excess runoff mechanism.

The present study utilized GIS capability to analyze topographical characteristics of the watershed in terms of wetness property of the land surface. Multi Criteria Evaluation (MCE) technique was integrated with GIS to rank/rate alternatives based on multiple criteria/factors that would affect erosion. MCE analysis of spatial information is an emerging approach and is efficient to analyze complex problems within a watershed (Setegn et al., 2009). MCE approach has been successfully used in many applications that involve decision making (Pereira and Duckstein, 1993; Malczewski, 2006; Hajkowicz and Higgins, 2008; Setegn et al., 2009; Greene et al., 2011). MCE technique is well assimilated in GIS environment. GIS is capable of efficiently storing, retrieving, transforming, displaying and analyzing spatial data. In this study, we used MCE technique within GIS environment to identify the actual source of erosion and map sensitive areas based on spatial dataset analysis. Weight of decision factors are assigned based on their relative effect to erosion process.

\section{Methods}

\section{Description of Study Area}

Koga River is a tributary to Gilgel Abay River which drains to Lake Tana in the Upper Blue Nile Basin. Koga dam (drainage area of around 22,000 ha) constructed downstream of the river, supply water for irrigating downstream farms. Koga dam is geographically located at $12^{0} 10^{\prime} \mathrm{N}$ latitude and $37^{0} 38^{\prime} \mathrm{E}$ longitude, within the Lake Tana Basin (Fig. 1). The annual rainfall is around $1480 \mathrm{~mm}$ based data available in an adjacent meteorological station, in Merawi. The dam was designed to store around 83 million metric cube of water to irrigate about 6,000 ha of command area (AfDB, 2001). The elevation of Koga watershed varies from 2,005 to 3,147 meter above sea level within the watershed based on Digital Elevation Model (DEM). Koga watershed falls under subtropical climate zone (Yeshaneh et al., 2013). The upstream of the watershed is narrow and mountainous while the downstream is wide and gentle slope.

\section{Data Requirement and Sources}

Data required for the MCE technique are spatial in nature. Four major types of data (Land use, DEM, Soil type and Rainfall) were collected. Data sources for each category presented in Table 1. There was no meteorological station found within the catchment. Nearby stations (Merawi, Adet, Dangila and Bahir Dar) were used to find the average rainfall using thiessen polygon method. The average rainfall was highly dominated $(\sim 97 \%)$ by a single adjacent station, Merawi. The variation of rainfall within the catchment was analyzed and found insignificant (with 95\% confidence). This was because of absence of closely installed meteorological stations within the catchment. As a result, rainfall was not considered as one of MCE criteria in this research.

After collecting the required data, spatial analysis were made to obtain MCE criteria map. Landsat 8 image together with intensive field point data collection were used to perform supervised land use classification in ArcGIS environment. The output map was validated and used to produce land use criteria map based on land use suitability classes. Soil map from Ministry of Water and Energy (MoWE) were directly used to produce soil criteria map based on soil type suitability classes. DEM with $30 \mathrm{~m}$ resolution was used to produce two criteria maps: Topographic wetness index and potential location of gullies. The wetness of the catchment (topographic 
wetness index) was predicted based on flow accumulation and slope of the particular pixel. Potential location of gullies was predicted based on threshold concept of two criteria: Wetness index and stream power index. Koga dam reservoir was considered as constraint. Each factor map (topography, potential locations of gullies, land use and soil) were reclassified based on sensitivity classes. The sensitivity classes for each factor were determined through discussion with experts (personal communication, T. Steenhuis, professor at Cornell University). Those experts have been doing intensive researches and experiments long on erosion and sediment transport process close to the study area.
Relative weights were assigned to each factor depending on the relevance of each factor and experts opinions. The value ( 1 to 9 and its reciprocal) were assigned to each factors based on pairwise comparison criteria. Pairwise comparison method was used to get the final weight of each factor. Based on factors final weight, the reclassified map was overlaid to get the combined effect of all actors. The output map was multiplied with the constraint map to exclude the reservoir area and produce the final erosion hotspot map. Figure 2 below presented the procedure to obtain the final erosion hotspot map. The detail of sensitivity classes for each factor and criteria layer map discussed in result section.

Table 1. Type and source of data

\begin{tabular}{ll}
\hline Data type & Sources \\
\hline DEM & United States Geographical Survey (USGS) website $^{\text {a }}$ \\
Land use & USGS website ${ }^{b}$ \\
Soil type & Ministry of Water and Energy (MoWE), Addis Ababa \\
Rainfall & National Meteorological Agency (NMA), Bahir Dar branch \\
\hline
\end{tabular}

a. http://gdex.cr.usgs.gov/gdex/

b. http://landsat.usgs.gov/landsat8.php
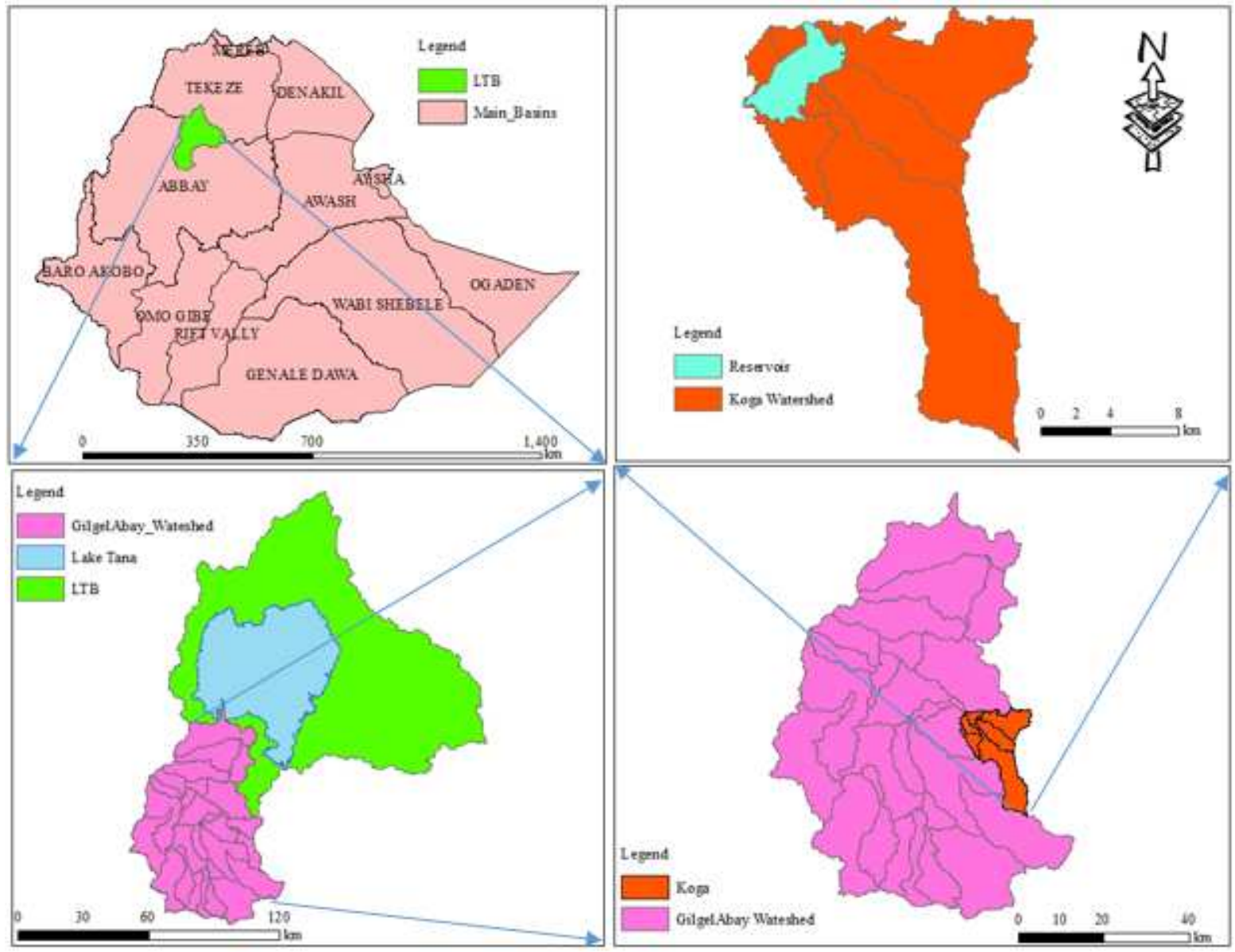

Fig. 1. Location map of koga watershed 


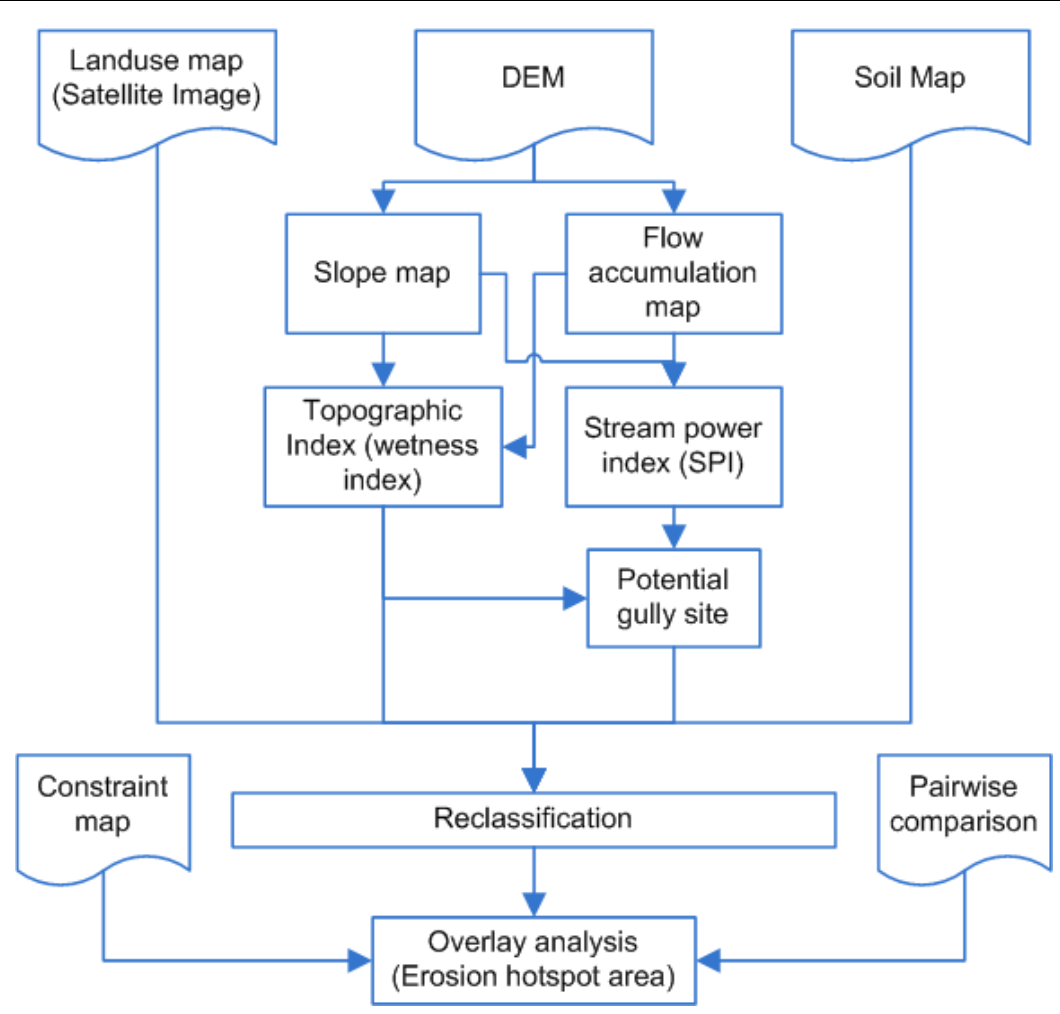

Fig. 2. Flow chart of the Methodology

\section{Factors Classification Approach}

Erosion sensitivity of the catchment is classified into two classes (i.e., sensitive and not-sensitive) based on FAO (1981) land classification framework for irrigation purpose. Sensitive classes are further classified depending on the degree of sensitivity while not sensitive classes are classified into two classes (currently not sensitive and permanently not sensitive) (Table 2). In this study, permanently not sensitive classes are described as constraint to erosion.

\section{Important Factors for Soil Erosion}

Four significant factors that can potentially affect soil erosion were considered. The first factor was land cover which controls the detachability and transport of soil particles and infiltration of water in to soil. The second was topography in terms of the wetness of the land. Soil types are important factor to erosion and sediment transport process depending on their physical and chemical properties. Locations of gullies were also considered as one major factor promoting erosion.

\section{Preparation of Criteria Maps}

Field work was carried out to collect control points for Landsat 8 satellite image supervised land use classification. Accuracy assessments were performed on classified images to determine how well the classification process accomplished the task using error matrix. Ministry of Water and Energy (MoWE) soil classification comparatively has finer resolution for the region and hence chosen for this study. It has 5 soil classes for Koga Watershed. Digital Elevation Model (DEM) of $30 \mathrm{~m}$ resolution was used to extract topographical parameters and potential location of gullies as well. The potential locations of gullies were predicted when both of the following two conditions of the thresholds were satisfied (Lulseged and Vlek, 2005): Stream Power Index (SPI) (Equation 2) >18 and Topographic Wetness Index (TWI) (Equation 1) $>6.8$. SPI indicates the possible source of erosion by concentrated flow detachment risk.

$$
\begin{gathered}
T W I=\operatorname{In}\left(\frac{A_{s}}{\tan \beta}\right) \\
S P I=\ln \left(A_{s} \tan \beta\right)
\end{gathered}
$$

where, $A_{S}$ is local upslope contributing area $\left(\mathrm{m}^{2}\right)$ from flow accumulation raster and $\beta$ is local slope angle (degree).

Area covered by Koga dam reservoir were considered constraint, area that could not promote erosion because of physical limitations. The constraint map has a value of 0 and 1 (Fig. 7), where 0 indicates constraint area. 
Table 2. Factors sensitivity class based on FAO (1981)

Sensitivity classes and notation

S1-Highly sensitive

S2-Moderately sensitive

S3-Marginally sensitive

S4 (N1)- currently not sensitive

\section{Explanation}

Factors significantly accelerate erosion

Factors clearly sensitive but has opportunity to reduce erosion

Factors significantly reduce erosion

Factors that cannot support erosion
The weight of factors are assigned based on their relative effect on erosion and ranked according to their relative importance order (Wale et al., 2012). Pairwise comparison based on (Saaty, 1977) was adopted to calculate the total weight of each factor. It provides a powerful and simplified selection criterion by reducing bias in decision making (Wale et al., 2012). It refers to the process of comparing factors in pairs to evaluate which one is preferred. Equal interval range method was applied to distribute the overall weight of factor maps. Weighted Overlay Tool in ArcGIS Spatial Analyst Toolbox environment was used to identify erosion sensitive areas (Nyerges and Jankowski, 2009).

\section{Results and Discussion}

\section{Impact of Land Use on Erosion}

Land use map is one of the most important factors that affect surface runoff and erosion in a watershed. It enables to assess the resistance of terrain unit to erosion as a result of surface protection. High erosion and quick response to rainfall are resulted from poor surface cover. From field visit, eight land use/land cover categories were distinguished followed by supervised land use classification method and maximum likelihood algorithm. Post-classification processing was applied to the classified image such as filtering and smoothing class boundaries. Filtering is the process used to remove fixed isolated pixels from classified image. Smoothing class boundaries is the process used to clump the classes and smooth's the ragged edge.

Accuracy assessments were performed on classified images to determine how well the classification process accomplished the task. It compares the classified image to an image which is considered to be correct (Google earth for this case) with the help of error matrix (Table 3). The error matrix compares the classified and correct image on a point by point basis. The points were generated randomly using ArcGIS random point generator tool (35 random points were generated for this case) within the boundary of Koga Watershed. The overall accuracy assessment resulted in acceptable range $(\sim 89 \%)$.

In Table 3, numbers in the first row and first column represent land use classes which are: 1 (Bare land), 2 (Bush land), 3 (Forest), 4 (Grass land), 5 (Intensively cultivated), 6 (Moderately cultivated), 7 (Urban/Village), 8 (Water). Similar row and column numbers combination indicates that the land use class in the classified image (Fig. 3a) is the same as the land use in the correct map (Google earth). For instance, (a) represents how many random points that are bare land in Google earth and bare land in the classified image. But (b) represents how many random points are bare lands in Google earth but bush land in the classified image. Finally, the overall accuracy is the total number of random points that are the same in both images per total number of sample random points: $(31 * 100 / 35) \sim 89 \%$. According to Anderson et al. (1976), $85 \%$ accuracy is considered acceptable for image classification.

Kappa coefficient provides an insight into land use classification whether or not better results are achieved than we would have achieved strictly by chance. Kappa coefficient is given below (Equation 3):

$$
\text { Kappacoefficient }=\frac{\begin{array}{c}
\text { observed accuracy } \\
1-\text { expected accuracy }
\end{array}}{\text { exped accuracy }}
$$

Observed accuracy, Equation 3, is the overall accuracy of image classification. Expected accuracy is calculated from the rows and column totals (Table 4).

Information from Table 3 was used to compute the value in Table 4. Column represented by "Total" from Table 3 multiplied with row represented by "Total" to produce the Kappa coefficient in Table 4. The product matrix was determined from the sum of the products of the diagonal matrix. Therefore, the Kappa coefficient is calculated as: Product matrix $(8+6+2+4+32+140+1+81=274)$, cumulative sum product $(1365)$, expected $(274 / 1365=0.201)$ and finally Kappa coefficient $(\sim 86.5 \%)$. Kappa coefficient value interpreted as the classification was $86.5 \%$ better than it would have occurred strictly by chance. Percent distribution of land use/cover and sensitivity classes in Koga Watershed presented in Table 5.

The re-classified land use map (Fig. 3b) indicated that $36.6 \%$ of the land use is highly sensitive; $34.6 \%$ moderately sensitive; $19.8 \%$ marginally sensitive; $4.4 \%$ currently not sensitive and about $7 \%$ constraint to erosion. 


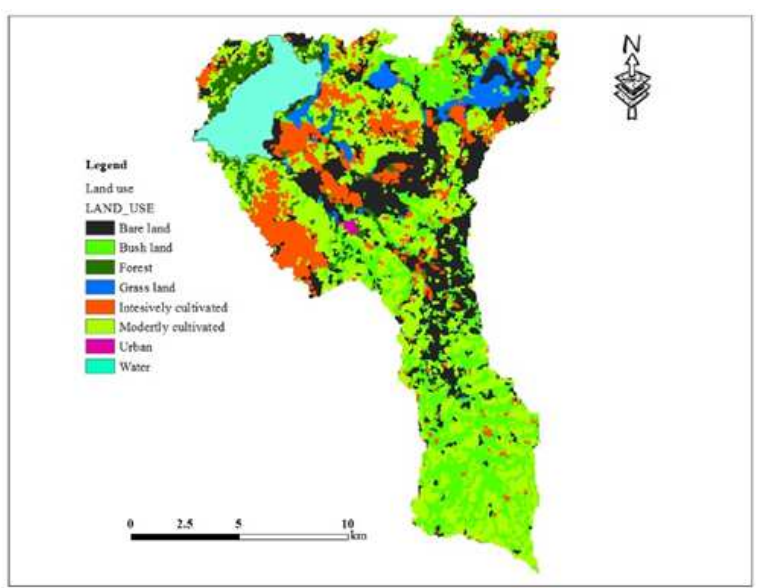

(a)

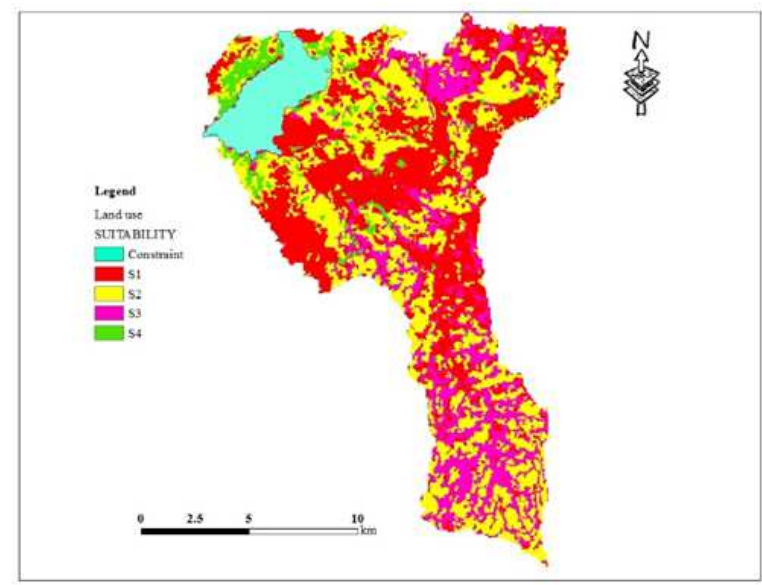

(b)

Fig. 3. (a) Land use map (b) Reclassified land use map

Table 3. Error matrix calculation for accuracy assessment

\begin{tabular}{llllllllll}
\hline & 1 & 2 & 3 & 4 & 5 & 6 & 7 & 8 & Total \\
\hline 1 & (a) 2 & (b) 0 & 0 & 0 & 0 & 0 & 0 & 0 & 2 \\
2 & 1 & 2 & 0 & 0 & 0 & 0 & 0 & 0 & 3 \\
3 & 0 & 0 & 1 & 0 & 0 & 1 & 0 & 0 & 2 \\
4 & 0 & 0 & 0 & 2 & 0 & 0 & 0 & 0 & 2 \\
5 & 1 & 0 & 0 & 0 & 4 & 3 & 0 & 0 & 0 \\
6 & 0 & 0 & 0 & 0 & 0 & 10 & 0 & 0 & 1 \\
7 & 0 & 0 & 0 & 0 & 0 & 0 & 1 & 0 \\
8 & 0 & 0 & 0 & 0 & 0 & 0 & 0 & 9 \\
Total & 4 & 2 & 1 & 2 & 4 & 14 & 1 & 9 & 31 \\
\hline
\end{tabular}

Table 4. Kappa coefficient calculation

\begin{tabular}{lrrrrrrrrr}
\hline & 1 & 2 & 3 & 4 & 5 & 6 & 7 & 8 & Total \\
\hline 1 & 8 & 4 & 2 & 4 & 8 & 28 & 2 & 18 & 2 \\
2 & 12 & 6 & 3 & 6 & 12 & 42 & 3 & 27 & 3 \\
3 & 8 & 4 & 2 & 4 & 8 & 28 & 2 & 18 & 2 \\
4 & 8 & 4 & 2 & 4 & 8 & 28 & 1 & 18 & 2 \\
5 & 32 & 16 & 8 & 16 & 32 & 112 & 8 & 72 & 8 \\
6 & 40 & 20 & 10 & 20 & 40 & 140 & 10 & 90 & 10 \\
7 & 1 & 2 & 1 & 1 & 4 & 14 & 1 & 9 & 1 \\
8 & 36 & 18 & 9 & 18 & 36 & 126 & 9 & 91 & 9 \\
Total & 4 & 2 & 1 & 2 & 4 & 14 & 1 & 9 & 31 \\
\hline
\end{tabular}

Table 5. Land use percent distribution and sensitivity classes

\begin{tabular}{lcl}
\hline Land use/cover & Area (\%) & Sensitivity class \\
\hline Bare land & 20.73 & $\mathrm{~S} 1$ \\
Bush land & 19.87 & $\mathrm{~S} 3$ \\
Forest & 4.42 & $\mathrm{~S} 4$ \\
Grass and marsh land & 3.70 & $\mathrm{~S} 2$ \\
Intensively cultivated & 13.27 & $\mathrm{~S} 1$ \\
Moderately cultivated & 30.97 & $\mathrm{~S} 2$ \\
Urban/village & 0.19 & $\mathrm{~S} 1$ \\
Water & 6.84 & Constraint \\
\hline
\end{tabular}

\section{Soil Type Impact on Erosion}

Soil type is one of the important factors that affect erosion process depending on the physical and chemical characteristics. It controls detachability of soil, soil particle transport and infiltration of water into the soil (Setegn et al., 2009). Soil texture is an important property which contributes to soil's erodibility. The watershed is dominated by Haplic Luvisols $(38.0 \%)$ followed by Haplic Alisols (24.3\%) which has moderately well drainage classes (Table 6). Figure 4a presented soil types in Koga Watershed.

The reclassified soil map (Fig. 4b) indicated that $17.5 \%$ of the soil is highly sensitive; $16.7 \%$ is moderately sensitive; 59 marginally sensitive and the remaining $(\sim 7 \%)$ is constraint to erosion.

\section{Impact of Topography on Erosion}

Topography is the major surface parameter for soil erosion assessment. Although slope has a great impact on soil erosion, the presence of soil erosion and heavy 
runoff on gentle slopes indicate that this phenomenon can occur without any need for a steep slope; the action of rain is enough (Fauck, 1956). Topographic Wetness Index (TWI) was used to describe the effect of topography based on saturated excess runoff generation mechanism. It represents spatial distribution of surface saturation and surface runoff which is important factor for soil erosion simulation. The concept was originally developed in the TOPMODEL framework (Beven et al., 1984) and described in Equation 1. As the contributing area increases and slope gradient decreases, topographic wetness index and soil moisture increases, it has higher correlation with saturation (Easton et al., 2010). Figure 5a presented topographic index map of Koga watershed. Erosion sensitivity class for topographic wetness index is presented in Table 7. The reclassified TWI map (Fig. 5b) indicated that $12.6 \%$ is highly sensitive; $44.3 \%$ moderately sensitive; $36.1 \%$ marginally sensitive and about $7 \%$ constraint to erosion.

\section{Impact of Gully on Erosion}

Gullies are large and deep erosion depression or channels that normally occur in drainage ways and not much deep (Imasuen et al., 2011). It occurs where surface water flow has become trapped in a small concentrated stream and begins to erode channels in the ground surface. To predict the sensitivity of a particular field to gully formation, threshold concept has been adopted. Stream power is the rate of energy of flowing water which is exerted on the bed and bank of a channel. Stream Power Index (SPI) is the product of watershed area and slope that indicates possible source of erosion by concentrated flow detachment risk (Equation 2). The potential locations of gullies are predicted based on SPI and TWI combination (Fig. 6a).

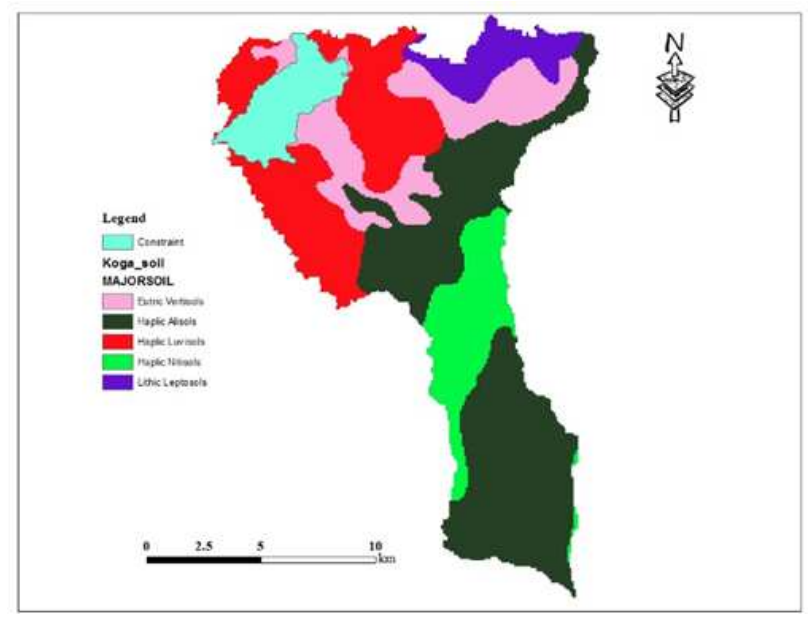

(a)

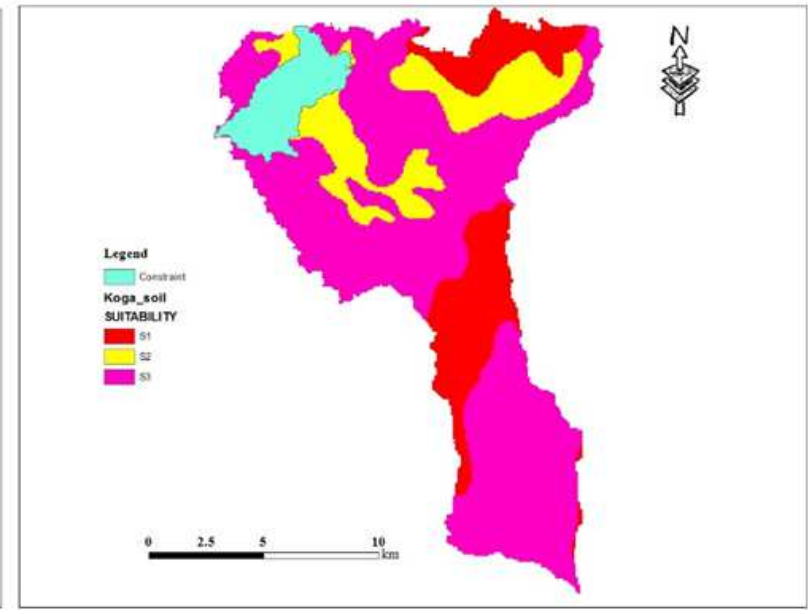

(b)

Fig. 4. (a) Soil map (b) Re-classified Soil map

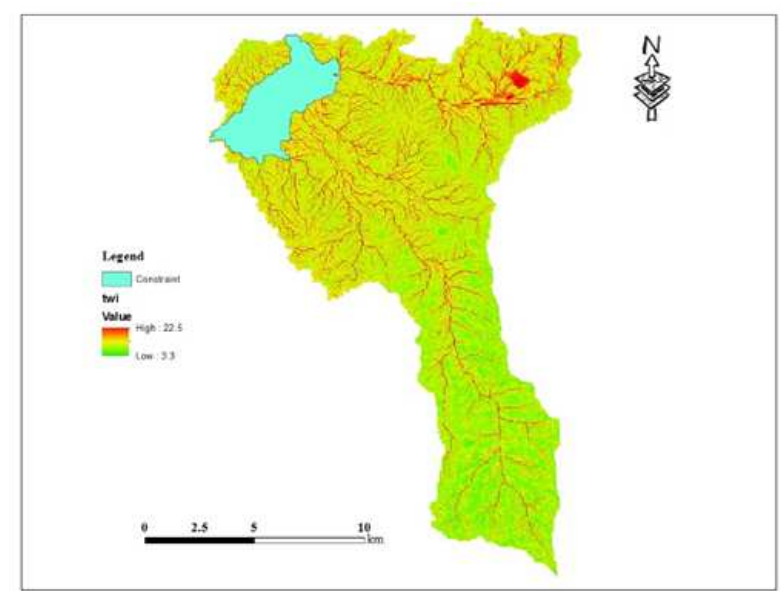

(a)

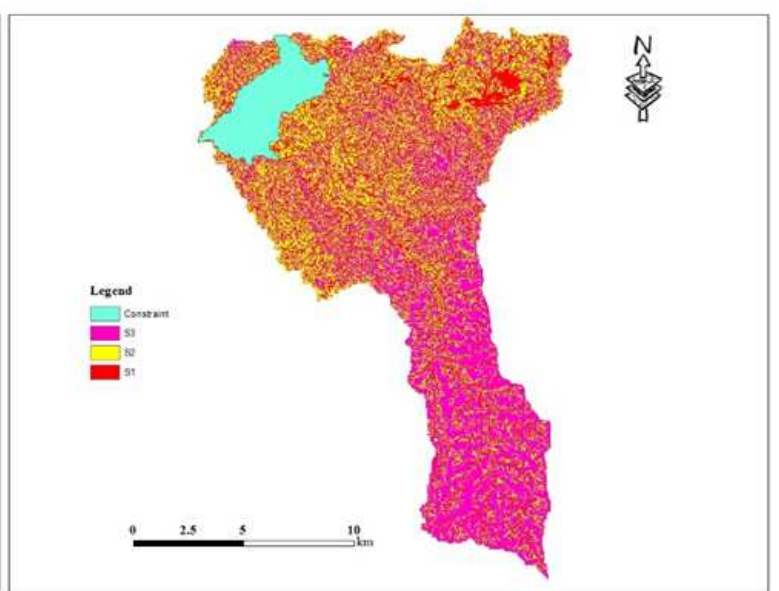

(b)

Fig. 5. (a) TWI map (b) Re-classified TWI map 


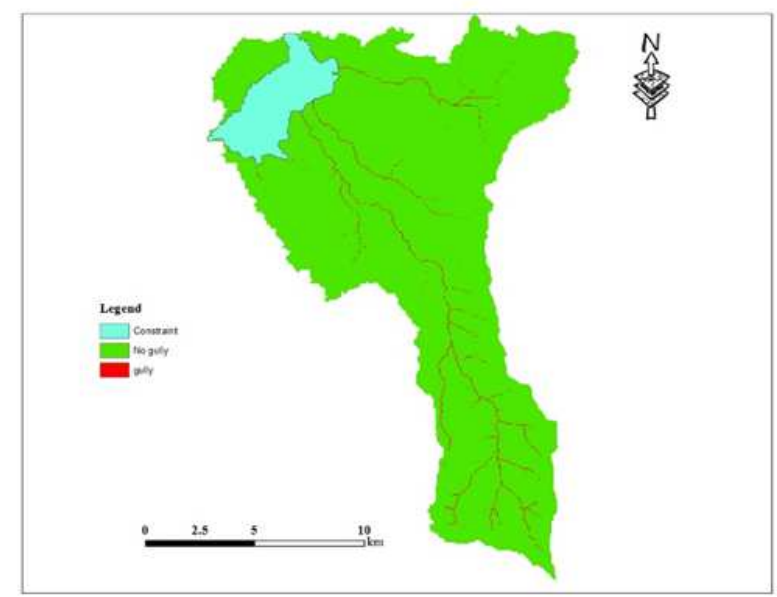

(a)

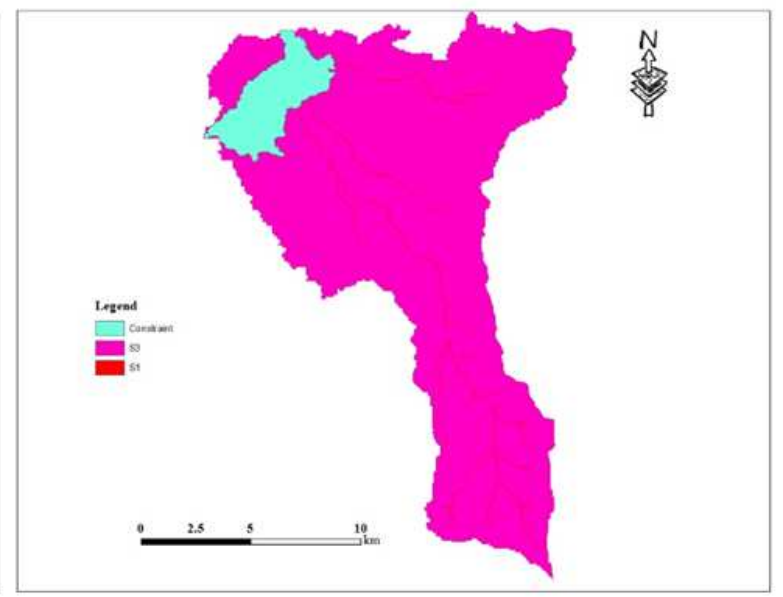

(b)

Fig. 6 (a) gully formation map (b) Re-classified gully map

Table 6. Soil type and percentage distribution

\begin{tabular}{|c|c|c|c|c|}
\hline & Drainage class & $\mathrm{AWC}(\mathrm{mm})$ & Area $(\%)$ & Sensitivity calss \\
\hline Eutric vertisols & Moderate & 125 & 20.09 & S2 \\
\hline Haplic alisols & Moderately well & 150 & 38.05 & S3 \\
\hline Haplic luvisols & Moderately wel & 150 & 24.32 & S3 \\
\hline Haplic nitisols & Poor & 50 & 11.22 & S1 \\
\hline Lithic leptosols & Imperfect & 15 & 6.30 & S1 \\
\hline
\end{tabular}

Table 7. Topographic wetness index sensitivity class

\begin{tabular}{ll}
\hline TWI & Erosion sensittivity group \\
\hline Up to 11.5 & $\mathrm{~S} 3$ \\
11.5 to 16.5 & $\mathrm{~S} 2$ \\
1.5 to High & $\mathrm{S} 1$ \\
\hline
\end{tabular}

Gully formation follows stream route and the map clearly shows that small gullies (plot level) were not capture by the threshold. Gully locations were given high sensitive class (S1) while no gully location less sensitive class (S3). The sensitivity classes were used to reclassify gully map (Fig. 6b).

Constrain map (Fig. 7) was prepared considering Koga reservoir. Value zero was given to the reservoir area to indicate permanently not suitable class. However, the sensitivity class for value 1 varies depending on the weight of other factors.

\section{Combined Effect of all Factors}

Pairwise comparison matrix was prepared by comparing factors one to one based on Pairwise comparison scale which is broken down from 1 to 9 . The highest value indicates absolute important and the reciprocal kept in the transpose position indicating absolute insignificant (Table 8). For example in Table 8 topographic index (on the left) is much more important from soil (on the top), then a value of 7 were assigned at their intersection topographic index row and soil column. Conversely, soil (on the left) of Table 8 is much less important than topographic index (on the top) therefore the reciprocal was assigned (i.e., 1/7). Among the major factors, soil type was considered as the least important factor. The eigenvector was calculated for each factor (rows). According to Podvezko (2009), eigenvector is defined as the $\mathrm{n}^{\text {th }}$ root of product of rows. The weights of factors were computed after normalizing the Eigen vector by its cumulative and multiplied by $100 \%$. The reliabilities of weights were checked by computing the consistency of comparison matrix which was found consistent.

The percent value of each factor was divided into four using equal interval method to assign value for each sensitivity classes (S1, S2, S3, S4). Each map was then summed up using raster calculator so that each pixel in that map had the sum of the four map values based on sensitivity classes (overlay analysis) (Fig. 8a). Finally, the total raster value was re-classified equally into four regions: Highly sensitive, moderately sensitive, marginally sensitive and currently insensitive (Fig. 8b). Zero value indicated constraint map.

The erosion sensitivity map indicated that $2 \%$ of the total watershed is highly sensitive (S1); $43 \%$ is moderately sensitive (S2); $16 \%$ marginally sensitive; $32 \%$ currently not sensitive and $7 \%$ constraint to erosion (reservoir) in Koga watershed. The result also indicated that major source of erosion is the low land area of the catchment. This is due to the gentle slope of catchment and especially areas near to the dam are flat and the 
ground water table is near to the surface (saturated areas). Saturated areas are found to be high source of erosion since the rainfall after saturation could not infiltrate more leading to high surface runoff. When there is high concentrated surface runoff the power of the stream will be higher to detach sediment particles and transport downstream. Furthermore, when the catchment is saturated the water inside has hydrostatic pressure head and needs only small reach like flow path to widen and slide the earth surface.

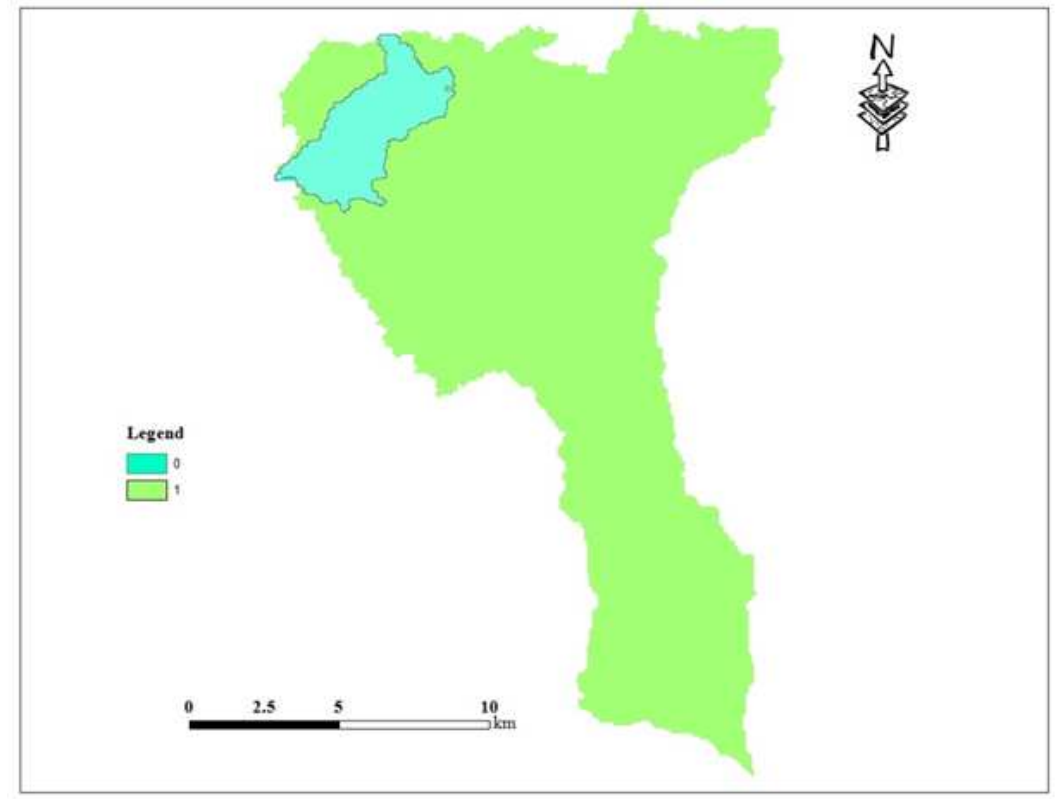

Fig. 7. constraint map

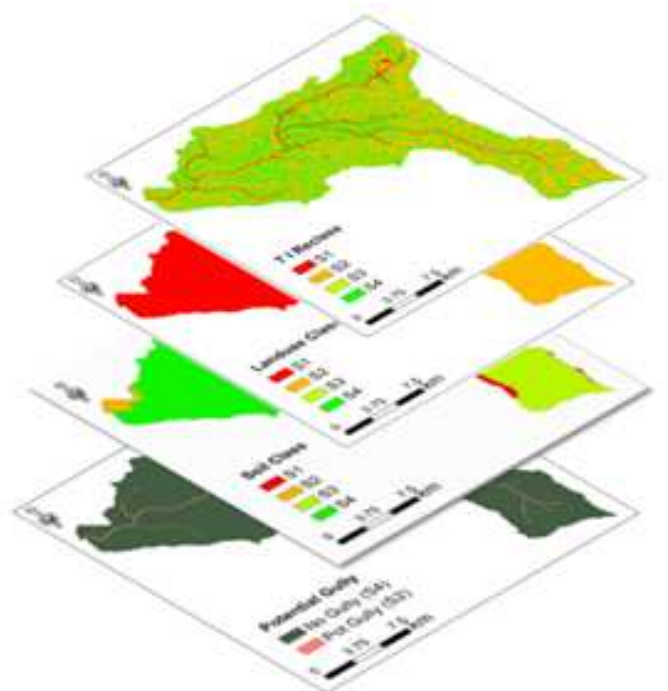

(a)

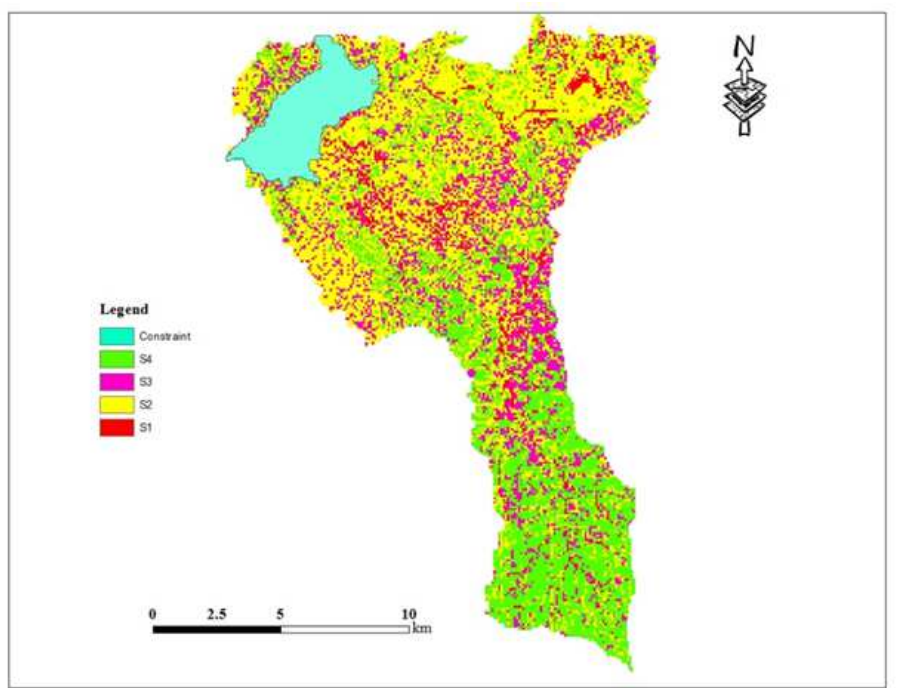

(b)

Fig. 8 (a) Overlay analysis (b) Erosion Sensitivity map

Table 8. Pairwise comparison matrix

\begin{tabular}{llllll}
\hline Factors & Topographic wetness index & Gully & Land use & Soil & Weight \\
\hline Topographic wetness index & 1 & 3 & 5 & 7 & 56 \\
Gully & $1 / 3$ & 1 & 3 & 5 & 26 \\
Land use & $1 / 5$ & $1 / 4$ & 1 & 4 & 13 \\
Soil & $1 / 7$ & $1 / 5$ & $1 / 4$ & 1 & 5 \\
\hline
\end{tabular}


The upland part of the watershed is found to be the least source of erosion. This is due to negligible saturation at the upland of the watershed and there is also source limit in some cases due to degraded and rocky areas. Furthermore, most of the gully formation which significantly affects erosion initiation is related to saturation while gully formation is negligible at the highland part of the watershed. Hence, it is essential to consider the saturated areas (low land) during design of watershed management strategies and implementation to effectively prevent soil loss from the catchment.

\section{Conclusion and Recommendation}

Multi-Criteria Evaluation (MCE) technique integrated with GIS has the potential to identify erosion hotspot area. The results in combination with proper field validation provide more accurate erosion sensitivity prediction. The threshold values for assessing the potential location of gullies (stream power index and wetness index threshold) were found to be high and hence did not capture catchment level small gully formations and hence further research on threshold value to capture catchment level gully formation would improve the result. The result could also be improved using higher resolution DEM.

The overall research indicated that most erosion hotspots areas were found in the lowland (more than $75 \%$ of erosion hotspot area) of the catchment, indicating that it is extremely important to consider the saturated areas during design of watershed management strategies.

\section{Acknowledgement}

We would like to acknowledge Water and Enregy (MoWE), Amhara National Regional State Water Resource and Development (ANRS-BoWRD) and National Meteorological Agency (NMA) Bahir Dar branch for providing necessary data for the study.

We also acknowledge Bahir Dar University for providing financial support needed for the study.

\section{Author's Contributions}

Monaj K. Jha: Analysis and interpretation of data, drafting and critically reviewing the manuscript and give final approval of the version.

Seifu A. Tilahun: Method design, analysis and interpretion of data and drafting the manuscript.

Ephrem Yetbarek: Method design, intensive field data collection and analysis.

Anwar A. Adem: Data acquisition, analysis and interpretation of data.

Abeyou W. Worqlul: Method design, analysis and interpretation of data and drafting the manuscript.

\section{Ethics}

This article is original and contains unpublished material. The corresponding author confirms that all of the other authors have read and approved the manuscript and no ethical issues involved.

\section{References}

AfDB, 2001. Arican Development Bank (AfDB). Koga irrigation and watershed management project appraisal report.

Anderson, J.R., E.E. Hardey, J.T. Roach and R.E. Witmer, 1976. A land use and land cover classification system for use with remote sensor data. U.S. Geological Survey professional paper 964, USGS, Reston, VA.

Beven, K., M. Kirkby, N. Schofield and A. Tagg, 1984. Testing a physically-based flood forecasting model (TOPMODEL) for three UK catchments. J. Hydrol., 69: 119-143. DOI: 10.1016/0022-1694(84)90159-8

Easton, Z., D. Fuka, E. White, A. Collick and B.B. Ashagre et al., 2010. A multi basin SWAT model analysis of runoff and sedimentation in the Blue Nile, Ethiopia. Hydrol. Earth Syst. Sci., 14: 1827-1841. DOI: $10.5194 /$ hess-14-1827-2010

FAO, 1981. Guidelines for designing and evaluating surface irrigation systems. Irrigation and Drainage Paper 45. FAO (Food and Agricultural Organization of the United Nation, Rome.

Fauck, R., 1956. Evolution of soils under mechanized cultivation in tropical areas. Proceedings of the Transection 6th International Congress Soil Science, (CSS' 56), pp: 593-596.

Greene, R., R. Devillers, J.E. Luther and B.G. Eddy, 2011. GIS-based multiple-criteria decision analysis. Geography Compass 5, 412-432. DOI: $10.1111 / \mathrm{j} .1749-8198.2011 .00431 . \mathrm{x}$

Hajkowicz, S. and A. Higgins, 2008. A comparison of multiple criteria analysis techniques for water resource management. European J. Operat. Res., 184: 255-265. DOI: 10.1016/j.ejor.2006.10.045

Imasuen, O., A. Omali and I. Ibrahim, 2011. Assessment of environmental impacts and remedies for gully erosion in Ankpa Metropolis and environs, Kogi State, Nigeria. Adv. Applied Sci. Res., 2: 372-384.

Lulseged, T. and P. Vlek, 2005. GIS-based landscape characterization to assess soil erosion and its delivery potential in the highlands of northern Ethiopia. Proceedings of the 1st International Conference on Remote Sensing and Geoinformation Processing in the Assessment and Monitoring of Land Degradation and Desertification, (ICRS ‘05), pp. 7-9. 
Malczewski, J., 2006. GIS-based multicriteria decision analysis: A survey of the literature. Int. J. Geographical Inf. Sci., 20: 703-726.

DOI: $10.1080 / 13658810600661508$

Mengstie, F.A., 2009. Assessment of Adoption Behavior of Soil and Water Conservation Practices in the Koga Watershed, Highlands of Ethiopia. 1st Edn., Cornell University, New York, pp: 124.

Nyerges, T.L. and P. Jankowski, 2009. Regional and Urban GIS: A Decision Support Approach. 1st Edn., Guilford Press, ISBN-10: 1606239066, pp: 299.

Pereira, J.M. and L. Duckstein, 1993. A multiple criteria decision-making approach to GIS-based land suitability evaluation. Int. J. Geographical Inf. Sci., 7: 407-424. DOI: 10.1080/02693799308901971

Podvezko, V., 2009. Application of AHP technique. J. Bus. Econ. Manage., 10: 181-189. DOI: 10.3846/1611-1699.2009.10.181-189

Reynolds, B., 2012. Variability and change in Koga reservoir volume, Blue Nile, Ethiopia. MSc Thesis, Upssala University, Sweden.

Saaty, T.L., 1977. A scaling method for priorities in hierarchical structures. J. Math. Psychol., 15: 234-281. DOI: 10.1016/0022-2496(77)90033-5

Setegn, S.G., R. Srinivasan, B. Dargahi and A.M. Melesse, 2009. Spatial delineation of soil erosion vulnerability in the Lake Tana Basin, Ethiopia. Hydrol. Processes, 23: 3738-3750.

DOI: $10.1002 /$ hyp.7476
Tilahun, S.A., C.D. Guzman, A.D. Zegeye, E.K. Ayana and A.S. Collick et al., 2014. Spatial and Temporal Patterns of soil erosion in the semiHumid Ethiopian Highlands: A Case Study of Debre Mawi Watershed. In: Nile River Basin, Melesse, A.M., W. Abtew and S.G. Setegn (Eds.), Springer International Publishing, Cham, ISBN-10: 3319027190, pp: 149-163.

Wale, A., A.S. Collick, D.G. Rossiter and T.S. Steenhuis, 2012. Irrigation area suitability mapping by multi-criteria evaluation technique for the case of Lake Tana Basin, Upper Blue Nile, Ethiopia. Proceedings of the Nile Basin Development Challenege Science Meeting on Rainwater Management for Resilient Livelihoods in Ethiopia, Jul. 9-10, Addis Ababa, Ethiopia.

Yeshaneh, E., W. Wagner, M. Exner-Kittridge, D. Legesse and G. Blöschl, 2013. Identifying land use/cover dynamics in the Koga Catchment, Ethiopia, from multi-scale data and implications for environmental change. ISPRS Int. J. Geoinform., 2: 302-323. DOI: 10.3390/ijgi2020302

Yilma, A.D. and S.B. Awulachew, 2009. Characterization and atlas of the Blue Nile Basin and its sub basins. Proceedings of the Intermediate Result Dessemination of workshop on Improved Water and Land Management in the Ethiopian Highlands: Its Impact on Downstream Stackeholders Dependent on the Blue Nile, Feb. 5-6, Addis Ababa, Ethiopia. 